Article

\title{
Design and Implementation of a High Quality Power Supply Scheme for Distributed Generation in a Micro-Grid
}

\section{Mingchao Xia * and Xiaoliang Li}

School of Electrical Engineering, Beijing Jiaotong University, Beijing 100044, China; E-Mail: 11121612@bjtu.edu.cn

* Author to whom correspondence should be addressed; E-Mail: mchxia@bjtu.edu.cn; Tel.: +86-138-111-08220; Fax: +86-10-5168-7101.

Received: 23 July 2013; in revised form: 12 September 2013 / Accepted: 17 September 2013 / Published: 23 September 2013

\begin{abstract}
A low carbon, high efficiency and high quality power supply scheme for Distributed Generation (DG) in a micro-grid is presented. A three-phase, four-leg DG grid-interfacing converter based on the improved structure of a Unified Power Quality Conditioner (UPQC, including a series converter and a parallel converter) is adopted, and improved indirect and direct control strategies are proposed. It can be observed that these strategies effectively compensate for voltage sags, voltage swells and voltage distortion, as well as voltage power quality problems resulting from the nonlinear and unbalanced loads in a micro-grid. While solving the coupling interference from series-parallel, the grid-interfacing converter can achieve proper load power sharing in a micro-grid. In particular, an improved minimum-energy compensation method is proposed that can overcome the conventional compensation algorithm defects, ensure the load voltage's phase angle stability, improve the voltage compensating ability and range, reduce the capacity and cost of converters, and reduce the shock of micro-grid switching between grid-connected mode and islanded mode. Moreover, the advantages/disadvantages and application situation of the two improved control strategies are analyzed. Finally, the performance of the proposed control strategies has been verified through a MATLAB/Simulink simulation under various operating conditions.
\end{abstract}

Keywords: high quality power; UPQC; voltage sags; three-phase four-leg converter; nonlinear and unbalanced loads; DG 


\section{Introduction}

A micro-grid is an effective way to develop low-carbon energy (such as wind power or photovoltaic power). Compared with the conventional centralized power grids, the micro-grid has the advantages of high efficiency energy utilization, excellent reliability and flexibility. However, the micro-grid environment is extremely complex due to its large randomness. Marnay [1] proposed a corresponding control strategy to meet users' various demands for power quality in which the load of the micro-grid is modeled as a pyramid structure: the loads on the bottom require lower quality power, and the ones at the top require higher quality power. Large nonlinear and unbalanced loads in a micro-grid will increase the degree of voltage imbalance, the total harmonic distortion rate, and produces a severe impact on the micro-power quality. Furthermore, the voltage distortion and voltage sags in the utility grid may produce a severe impact on the voltage and current quality at the point of common coupling (PCC) between the micro-grid and the utility grid, and they also impact the power sharing on the micro-grid. Li et al. [2] proposed an architecture of a series-parallel converter in view of the utility grid voltage imbalance and current-limiting demand in case of a grid fault. This structure could effectively eliminate the negative-sequence current caused by a utility grid voltage imbalance, but it fails to consider the impact of nonlinear and unbalanced loads on a system in the micro-grid. In view of the fundamental negative sequence problem of the utility grid voltage, the dq0 double-sequence control strategy, which could efficiently eliminate the fundamental negative sequence voltage but could not resolve the problem of voltage distortion was proposed [3]. A converter architecture composed of three single-phase inverters for a micro-grid with unbalanced and nonlinear loads was presented in [4,5]. This architecture was suitable for a high power grid but did not consider the impact of voltage distortion and voltage sags on the PCC in a utility grid. Wang et al. [6] proposed compensating for the negative sequence voltage by changing the negative sequence current to search and compensate for the minimal value of the voltage amplitude by changing the output current amplitude and phase of the grid-connected converter but did not consider the capacity of the compensation power. In [7,8] a degraded-order compensation algorithm and reduced a third-order system to a first-order system to avoid system resonance was proposed. To improve the transient response in a micro-grid, Papadimitriou et al. [9] presented a fuzzy control theory that could restrain the power imbalance during the transition of the micro-grid from grid-connected mode to islanded mode. Zamani et al. [10] proposed a closed-loop control strategy that enabled the micro-grid to maintain good power quality without switching modes. In [11] the control strategy of power sharing between the utility grid and the micro-grid based on a back-to-back converter that suppresses the interference on the micro-grid caused by the frequency change at the PCC was proposed. In view of the energy storage problem in the micro-grid, Shi et al. [12] proposed a novel extended-single-phase shift control strategy based on an efficient bidirectional full-bridge DC-DC converter; meanwhile, Zhang et al. [13] presented a coordination control strategy of solid oxide fuel cells and superconducting energy storage.

In consideration of the drawbacks of the systems presented in the above papers, a micro-grid control strategy based on an improved UPQC structure is proposed, whose physical architecture includes a Dynamic Voltage Restorer (DVR) added to the left side of the conventional UPQC architecture to improve the robustness of the micro-grid operation by coordination control. The control strategies proposed in this paper are divided into improved indirect control and improved direct control, and both can reduce the degree of voltage unbalance, achieve current harmonic compensation and provide proper 
power sharing in the micro-grid. They can also eliminate the impact of voltage sags, voltage swells, and distortions in the utility grid on the micro-grid when transitioning from grid-connected mode to islanded mode. In particular, an improved minimum-energy method for voltage sag compensation is proposed by improving the UPQC architecture at the PCC in the micro-grid to overcome the defects of the conventional compensation algorithm and to ensure that the phase angle jump will not occur on the load voltage. The proposed system could improve the capability and scope of a DG compensating voltage and reduce the capacity and cost of converters. The effectiveness of the proposed control strategy has been verified with a MATLAB/Simulink simulation under various operating conditions.

\section{The Application of a Three-Phase Four-Leg Series-Parallel Converter in a Micro-Grid}

This paper mainly studies how a micro-grid can provide an efficient and high quality power supply in the presence of external and internal interferences; the former refers to the interference of voltage sags, voltage swells and voltage distortion at the PCC on the micro-grid; the latter refers to the interference of non-linear loads and unbalanced loads on the micro-grid. The DG position and capacity in the micro-grid are essential to the stability of the micro-grid operation and differ from the existing micro-grid architecture [13-15]. In [16,17] a micro-grid architecture based on UPQC to solve these problems, as shown in Figure 1 was proposed (this paper targeted a three-phase four-wire $380 \mathrm{~V}$ system).

Figure 1. Application of series-parallel converters in a micro-grid.

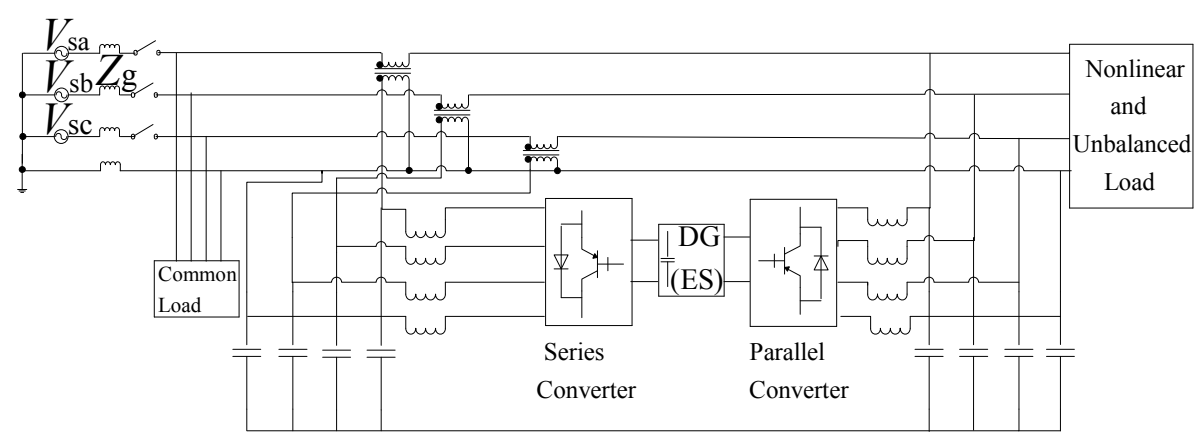

After comprehensive analysis, three typical topological architectures are found and shown in Figure 2 (for the sake of simple analysis, a single phase architecture design is shown in the figure, and the nonlinear and unbalanced loads are local loads of the DG in the figure). Among them, the left-series right-parallel is the most widely used.

The left-series right-parallel topological structure is adopted in this paper. Similar to the control of the UPQC, its control strategies are mainly divided into indirect control and direct control. In the indirect control strategy, the series converter is controlled as a non-sinusoidal voltage source. It can produce the corresponding vector difference caused by a fault voltage in the utility grid, which satisfies the requirement that the grid-connected voltage is parallel and symmetrical as well as the requirement for a three-phase voltage in the same phase of the fundamental positive sequence of the utility grid voltage. The parallel inverter is controlled as a non-sinusoidal current source, and it can eliminate the harmonic current caused by a nonlinear and unbalanced load in the micro-grid to maintain the unit power factor in grid-connected mode. In the direct control strategy, the series converter is controlled as a sinusoidal current source, and it can use the current source nature with stronger impedance to harmonic voltage to 
block its interference with the voltage in the load terminal. The parallel converter is controlled as a sinusoidal voltage source and uses the voltage source nature with smaller impedance to harmonic current, which can absorb the harmonic and reactive current while maintaining the rated voltage in the load terminal. A direct control strategy is adopted in [7], and its primary drawback is the inability to solve the problems of voltage sags with a phase angle jump. Considering the above problem, the improved indirect control strategy and the improved direct control strategy are adopted, and a comparison is made between the two methods.

Figure 2. Three types of typical structures: (a) left-series right-parallel structure; (b) right-series left-parallel structure; (c) hybrid structure.

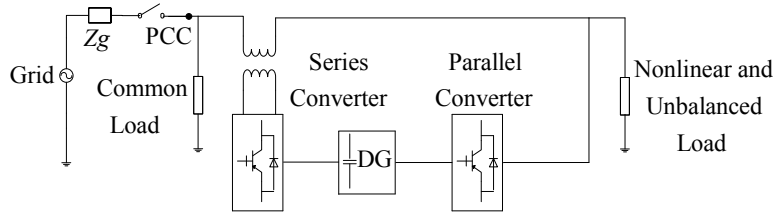

(a)

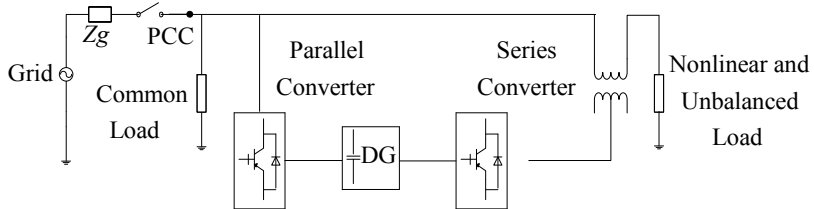

(b)

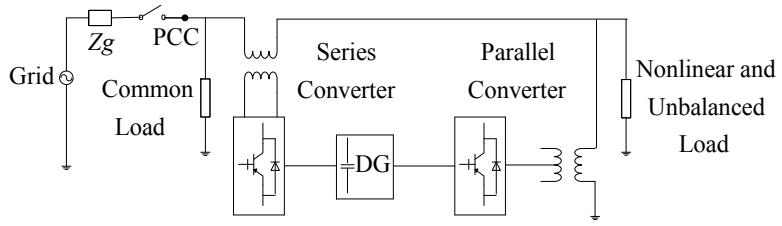

(c)

\section{The Structure and Control Strategy of a Micro-Grid}

\subsection{Existing Micro-Grid Architecture Based on UPQC}

The existing micro-grid architecture based on UPQC is shown in Figure 1. Figure 3a,b are single-line equivalent circuit diagrams with indirect control and direct control, respectively. The dashed part in Figure $3 \mathrm{~b}$ indicates the isolation voltage of the series converter and the harmonic current absorbed by the parallel converter, among which the series parallel converters display the problem in the form of a voltage source and a current source to be solved in the main circuit.

Figure 3. Single-line equivalent diagram: (a) indirect control; (b) direct control.

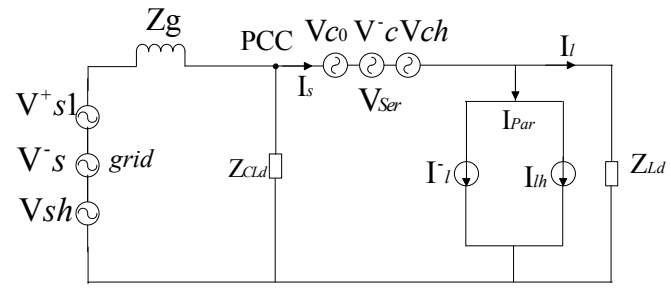

(a)

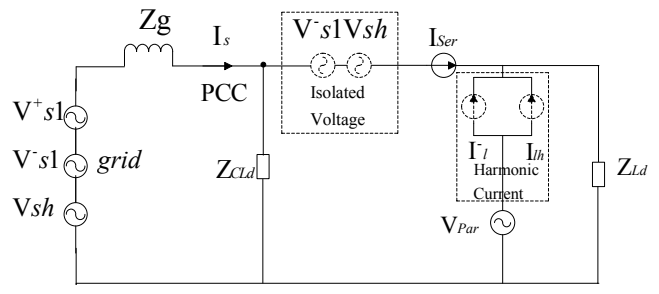

(b)

PCC denotes the point of common coupling, and $V_{s}$ denotes the voltage in the utility grid; "1" denotes the fundamental components; " 0 " denotes the zero sequence components; "+" denotes the positive sequence components; "-" denotes the negative sequence components; and "h" denotes all 
harmonic components. "Ser" represents the series converter; "Par" represents the parallel converter; $I_{s}$ represents the grid-connected current; $V_{c}$ represents the compensation voltage of the series converter; $I l$ represents the current of the load; $Z_{L d}$ represents the non-linear and unbalanced load; $Z_{C L d}$ represents the common load; and $Z_{g}$ represents the impedance of the transmission line of the utility grid. All signs in this paper refer to the above denotations.

\subsection{Conventional Voltage Sag Control Strategies of UPQC}

Voltage sag is often accompanied with a phase-angle jump and is a means of judging whether the phase of the load voltage changes before and after compensation. The control strategies are divided into three methods: the constant-phase voltage compensation, the in-phase voltage compensation, and the minimum-energy compensation (advanced-phase voltage compensation). The common feature of the three compensation methods is that the amplitude of the load voltage remains constant after the compensation (as shown in Figure 4). $\dot{U}_{s}$ is the voltage before the utility grid voltage sag; $\dot{U}_{s}^{\prime}$ is the voltage after the voltage sag; $\dot{U}_{l}$ is the load voltage after compensation; $\dot{U}_{c}$ is the compensation voltage of the series converter; $\delta$ is the phase of the voltage sag in the utility grid; $\delta$ is the phase difference between $\dot{U}_{l}$ and $\dot{U}_{s}^{\prime} ; \varphi$ is the load equivalent phase angle; $\beta$ is the phase between the compensation voltage $\dot{U}_{c}$ and the voltage sag $\dot{U}_{s}^{\prime}$; and $I_{s}$ is the grid-interfacing current. Through control strategies, the voltage amplitude on the load terminal remains constant. As shown in Equation (1), the compensation voltage $U_{c}$, the active power $P_{c}$ and the apparent power $S_{c}$ can be deduced from Figure 4.

$$
\left\{\begin{array}{l}
U c=\sqrt{U^{2} l+U^{\prime 2}{ }_{s}-2 U_{l} U_{s}^{\prime} \cos \delta^{\prime}} \\
P_{c}=3 I_{s}\left(U_{l} \cos \delta^{\prime}-U^{\prime} s\right) \\
S_{c}=3 I_{s} \sqrt{U^{2}{ }_{l}+U^{\prime 2}{ }_{s}-2 U_{l} U_{s}^{\prime} \cos \delta^{\prime}}
\end{array}\right.
$$

Figure 4. Vector diagram of voltage sags.

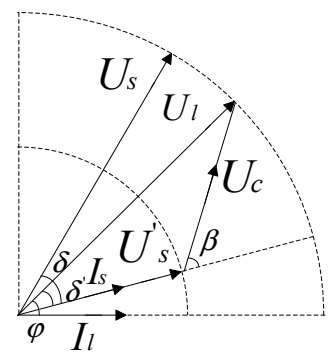

(a) The Constant-Phase Voltage Compensation

The constant-phase voltage compensation is shown in Figure 5a, where the load voltage amplitude and phase remain constant after compensation. It can be found from Equation (1) that this method needs a larger apparent power and compensation voltage; therefore, the converter needs a larger compensation range and capacity. In addition, when the jump-angle $\delta$ is larger, a reactive power over-compensation may occur. However, restricted by the DG capacity and the converter power rating, this method can only compensate for a limited voltage sag amplitude and jump angle. As shown in Figure $5 \mathrm{~b}$ with $U_{c m a x}$ 
being the maximum amplitude of the DG compensation voltage, $U_{s}^{\prime}$ being the amplitude after voltage sag, and $\delta$ being the random jump angle, the range of compensation voltage $\dot{U}_{c}$ is from $\dot{U}_{c 1}$ to $\dot{U}_{c 2}$, whose compensation angle is $\theta_{c}$. Although the phase of load voltage is compensated, the voltage amplitude is not fully compensated. What's worse, compensation angle $\theta_{c}$ will become increasingly smaller when jump angle $\delta$ becomes larger. If the load voltage amplitude and phase remain constant after constant-phase voltage compensation, the allowed maximum dropout amplitude $U_{s \max }^{\prime}$ and the allowed maximum jump angle $\delta_{\max }$ are analyzed in Figure 5c and in Equation (2):

$$
\left\{\begin{array}{l}
U_{s \max }^{\prime}=U_{l} \cos \delta+\sqrt{U^{2}{ }_{c \max }-U^{2}{ }_{l} \sin ^{2} \delta} \\
\delta_{\text {max }}=\arcsin \frac{U_{c \max }}{U_{l}}
\end{array}\right.
$$

Figure 5. The constant-phase voltage compensation: (a) relations of $U_{s}^{\prime}, U_{c}$ and $U_{l}$; (b) the range of load voltage after compensation while keeping phase angle constant; (c) the allowed maximum dropout amplitude and jump angle of $U_{s}^{\prime}$ to keep $U_{l}$ amplitude and angle constant.

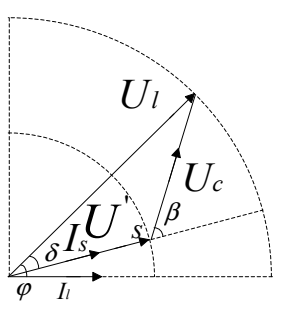

(a)

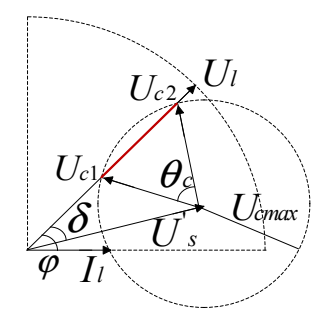

(b)

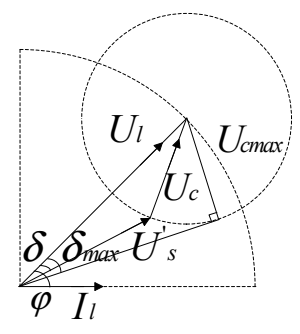

(c)

(b) In-Phase Voltage Compensation

In-phase voltage compensation is shown in Figure 6. It can be found from Equation (1) that this method needs the minimum apparent power and voltage amplitude but provides the maximum active power; in addition, at the start of compensation, the phase angle of the load voltage changes by $\delta$; namely, $\dot{U}_{l}$ becomes $\dot{U}_{l}^{\prime}$ and $\dot{I}_{l}$ becomes $\dot{I}_{l}^{\prime}$, which can cause serious consequences to a load that is rather sensitive to phase jump.

Figure 6. The in-phase voltage compensation.

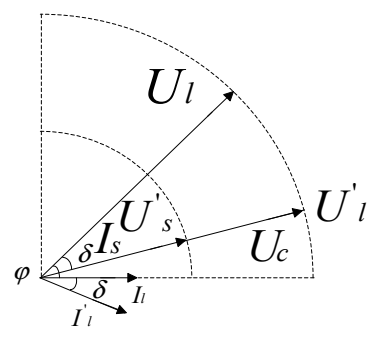


(c) The Minimum-Energy Compensation

The minimum-energy compensation method [18-20] can exceed the voltage sag $\dot{U}_{s}^{\prime}$ by a certain phase $\beta$ and reduce the $\dot{U}_{c}$ component on $\dot{I}_{s}$ to reduce the injected active power via the injecting compensation voltage $\dot{U}_{c}$. However, this method's greatest drawback is that it sometimes needs a larger amplitude compensation voltage, and it is easy to cause a large jump angle of the load voltage phase, which can lead to a great loss to power users.

\section{The Improved Indirect Control Strategy Base on an Improved Structure of the UPQC}

\subsection{Micro-Grid Based on an Improved Structure of the UPQC}

For the disadvantages of the conventional constant phase voltage compensation method, in-phase voltage compensation method and the minimum-energy compensation method, a DVR is added on the left of the conventional UPQC architecture to improve the UPQC architecture at the PCC of the micro-grid. An improved minimum-energy compensation method is also proposed. After the comprehensive analysis, there are two structures available for reference, as shown in Figure 7.

Figure 7. The diagram of two types of improved structures. (a) topological structure 1;

(b) topological structure 2 .

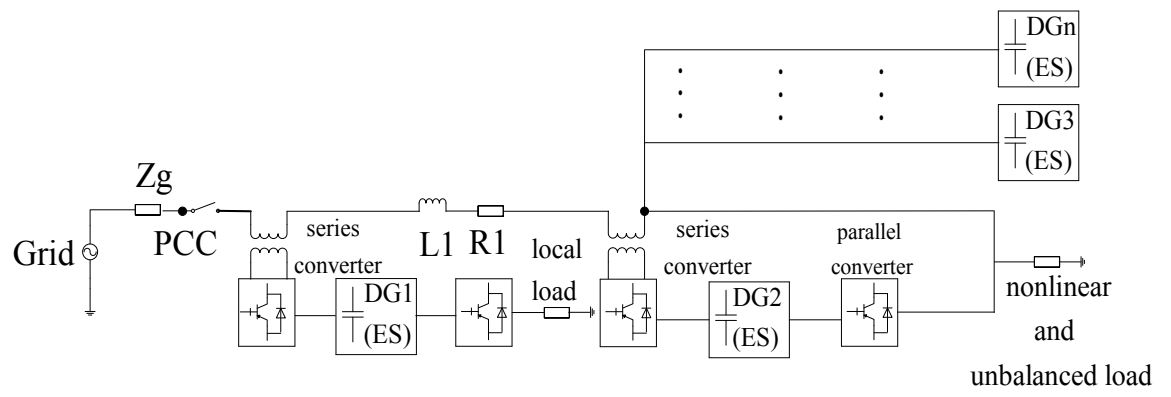

(a)

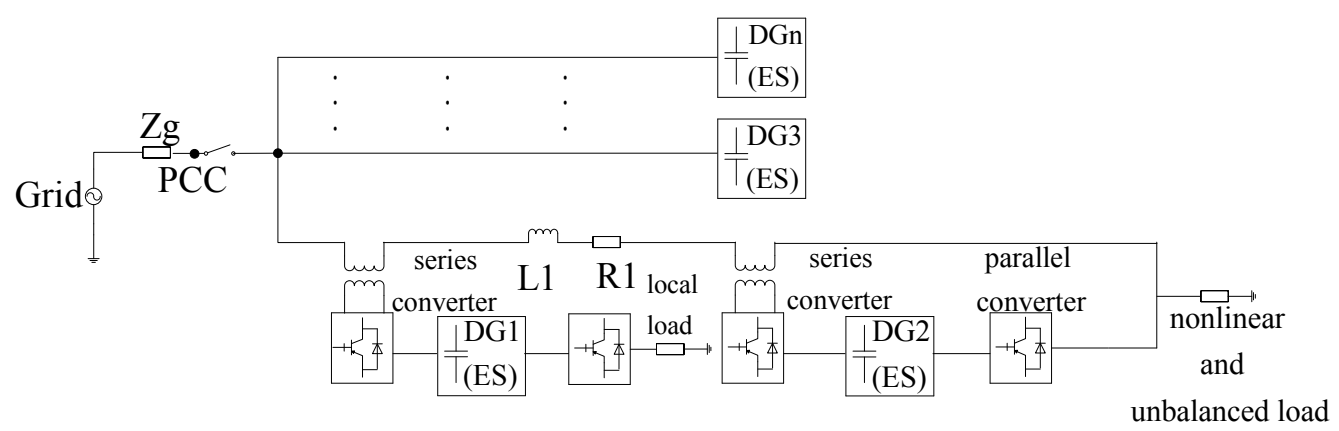

(b)

PCC denotes the point of common coupling, DG denotes the Distributed Generation, and ES denotes the Energy Storage system. Figure 7a,b are similar in voltage compensation by DG1 and DG2, but differ in the position of other DGs. Compared with Figure 7b, Figure 7a has the advantage of only accounting for the impact of the fault voltage at the PCC on the micro-grid once. Thus, Figure 7a is adopted in this paper, and the simplified main circuit wiring drawing is shown in Figure 8. 
Figure 8. Employed configuration of the grid-interfacing converter system.

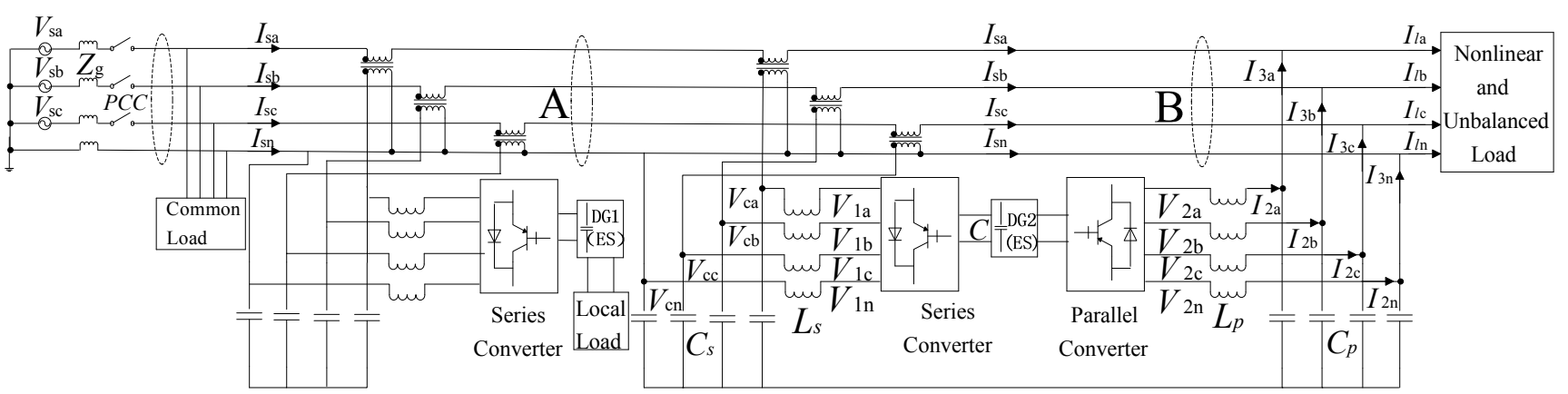

Therein, before the voltage sag at the PCC, the converter on the left of DG1 is controlled as a sinusoidal current source in grid-connected mode. The concrete control principals of this converter are shown in Figure 16 in Section 5.1, and its role is to provide current for other DGs in the micro-grid or to store energy for DG1's energy storage system. After a voltage sag at the PCC, the converter on the left of DG1 is switched to be a voltage source to apply control. The control block diagram of this converter is shown in Figure 9. First, determine if there is a phase jump in the case of a voltage sag. If there is a phase jump, DG1 and DG2 coordinate the compensation; their control procedures are shown in Section 4.2.1 below; if there is not a jump ( $\delta=0)$, it is necessary to judge the amplitude of the voltage sag and whether it is beyond the DG compensation limit ( $\Delta U>\Delta U_{\text {ref }}, \Delta U$ is the amplitude of voltage sags, $\Delta U_{\text {ref }}$ is compensation limitation of DG). If so, it is necessary for DG1 and DG2 to conduct in-phase compensation jointly.

Figure 9. Block diagram of the coordination control.

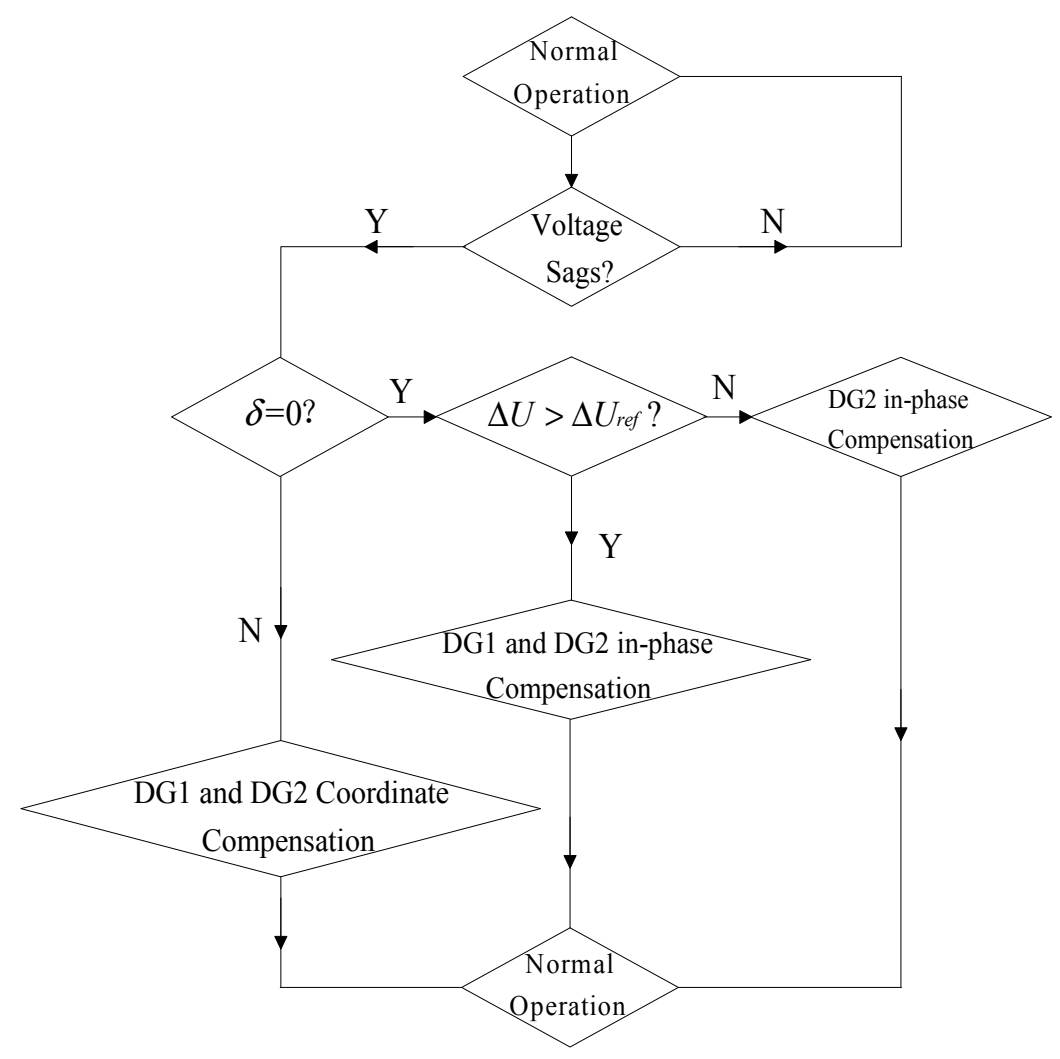


Through the coordination control of series-parallel converters, the objective to be accomplished by its improved control strategy is shown in Figure 10 (the voltage and current correspond to vectors in dq0 coordinate in Figure 8).

Figure 10. Block diagram of the overall control targets. (a) Block diagram of the series converter control targets; (b) Block diagram of the parallel converter control targets.

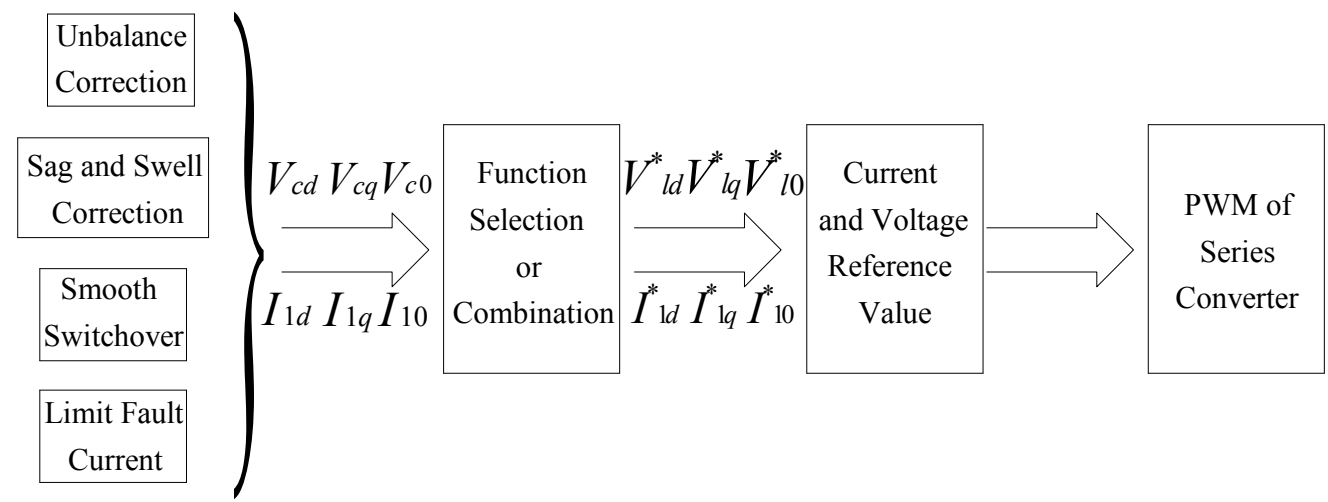

(a)

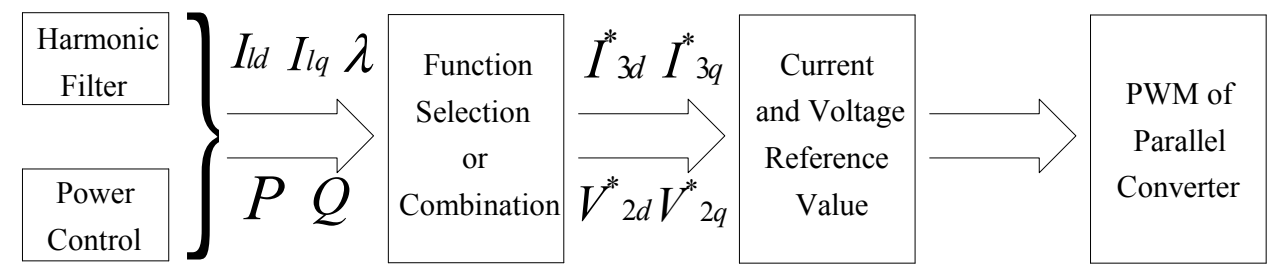

(b)

\subsection{Control of the Series Converter}

After voltage sags at the PCC, the DG1 and DG2 series converter are controlled as a non-sinusoidal voltage source whose control principle diagram is shown in Figure 11. N denotes the transformer ratio; PR denotes the proportion resonant controller, which can track the different frequency components for obtaining zero steady-state errors and the control equation is shown in Equations (3) and (4) in the dq0 coordinate ( $\omega_{\text {cutm }}$ denotes low-frequency cutoff).

Figure 11. Control diagram of the series converter.

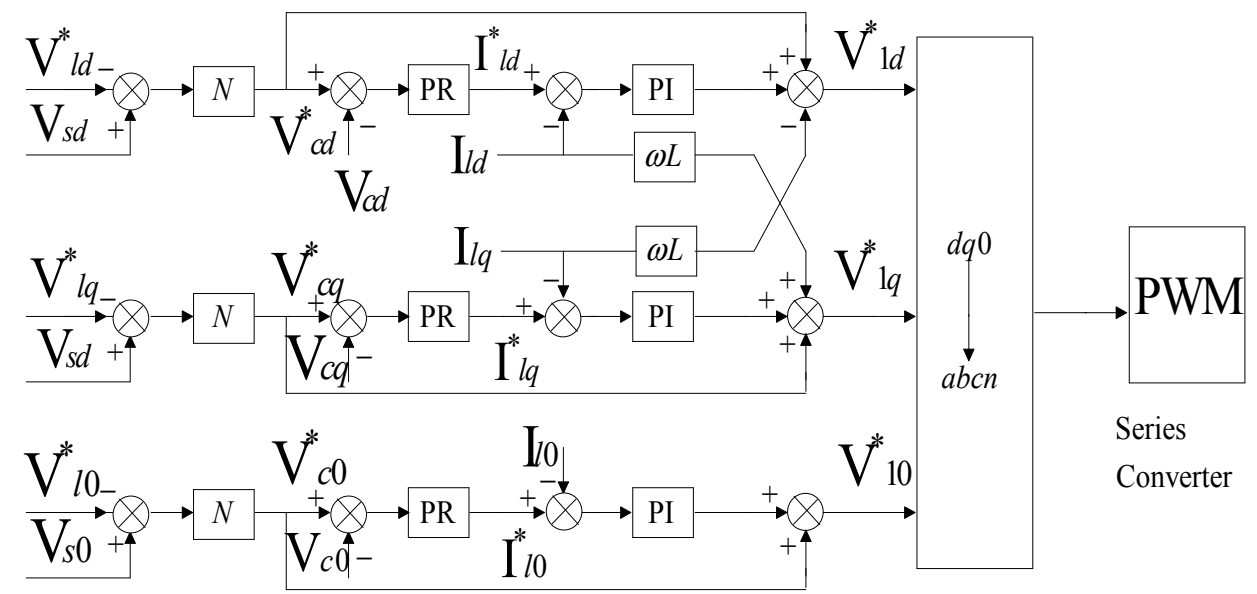




$$
\begin{aligned}
& \left\{\begin{array}{l}
G_{n s}(P R)=K_{P}+\sum_{m=1,3,5 \ldots n} \frac{2 K_{i} \omega_{c u t m} S}{s^{2}+2 \omega_{c u t m}+(m \omega)^{2}} \\
I^{*}{ }_{1 d}=G_{n s}(P R) \cdot\left(V^{*}{ }_{c d}-V_{c d}\right) \\
I^{*}{ }_{1 q}=G_{n s}(P R) \cdot\left(V^{*}{ }_{c q}-V_{c q}\right) \\
I^{*}{ }_{10}=G_{n s}(P R) \cdot\left(V^{*}{ }_{c 0}-V_{c 0}\right)
\end{array}\right. \\
& \left\{\begin{array}{l}
V^{*}{ }_{1 d}=G_{n s}(P I) \cdot\left(I^{*}{ }_{1 d}-I_{1 d}\right)+V^{*}{ }_{c d}-\omega L_{1} I_{1 q} \\
V^{*}{ }_{1 q}=G_{n s}(P I) \cdot\left(I^{*}{ }_{1 q}-I_{1 q}\right)+V^{*}{ }_{c q}+\omega L_{1} I_{1 d} \\
V^{*}{ }_{10}=G_{n s}(P I) \cdot\left(I^{*}{ }_{10}-I_{10}\right)+V^{*}{ }_{c 0}
\end{array}\right.
\end{aligned}
$$

\subsubsection{The Improved Indirect Control Strategy}

In the coordinate compensation of DG1 and DG2, there are two coordination methods: (1) DG1 adopts the improved minimum-energy compensation method and compensates voltage sags $\dot{U}_{s}$ to $\dot{U}_{s}^{\prime}$ by compensation voltage $\dot{U}_{c 1}$; DG2 adopts the in-phase voltage compensation and compensates the voltage $\dot{U}_{s}^{\prime}$ to $\dot{U}_{l}$ by compensation voltage $\dot{U}_{c 2}$. The control method is shown in Figure 12a; (2) DG1 adopts the in-phase voltage compensation approach, and DG2 adopts the improved minimum-energy compensation method, whose control method is shown in Figure 12b. After comparison with Figure 12c, the active voltage $U_{c p}$ and reactive voltage $U_{c q}$ of the two compensation methods are the same. Compared with method 2, method 1's advantage is that after DG1 compensation, the voltage sag $\dot{U}_{s}$ is compensated to $\dot{U}_{s}^{\prime}$, which makes the sag jump angle $\delta=0$. For this reason, compensation method 1 is adopted in this paper.

Figure 12. Compensation strategies and comparison: (a) Compensation method 1; (b) Compensation method 2; (c) Comparison between compensation method 1 and method 2; (d) Comparison between compensation method 1 and the conventional compensation method.

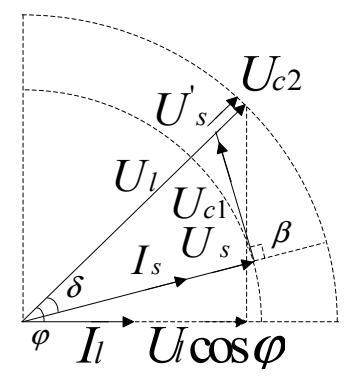

(a)

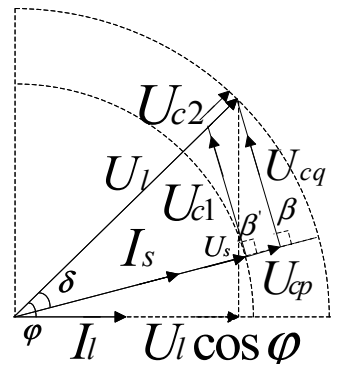

(c)

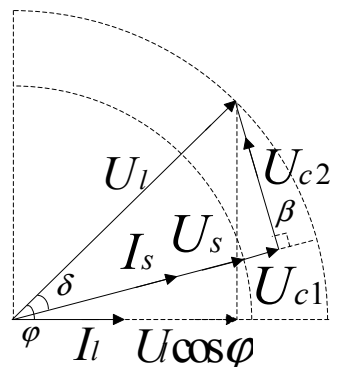

(b)

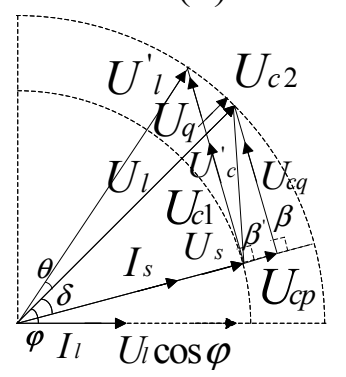

(d) 


\subsubsection{Comparison between Conventional Minimum-Energy and Improved Minimum-Energy Compensation}

In the conventional minimum-energy compensation approach, $\beta^{\prime}$ is dynamic and may approach $90^{\circ}$ as far as possible by finding the optimal point. In the case of $U_{l} \cos \varphi<U_{s} \leq U_{l}$, the optimal point can be found to obtain $\beta^{\prime}=90^{\circ}$ to make the active power of the injection system be zero, whose corresponding reactive voltage is $U_{q}$ and the apparent power is $S_{c}=P_{c}=I_{s} U_{q}$.

The improved minimum-energy compensation method can apply compensation by the coordination control of DG1 and DG2, as shown in Section 4.2.1. According to Figure 13d, $U_{c}^{\prime}=\sqrt{U_{c p}^{2}+U_{c q}^{2}}$ can be obtained and its apparent power is $S_{c}^{\prime}=I_{s} \sqrt{U^{2}{ }_{c p}+U^{2}{ }_{c q}}=I_{s} U_{c}^{\prime}$. As shown in the figure, $U_{q}>U_{c}^{\prime}$, which means $S_{c}>S_{c}^{\prime}$. After comparison between this method and the conventional minimum-energy compensation method, although the active power $\Delta P=I_{s} U_{c p}$ increases, the apparent power $S_{c}^{\prime}$ decreases. Specifically, the load voltage $\dot{U}_{l}$ has no phase angle $\theta$ change, which is of vital importance to the protection of a load that is rather sensitive to phase jump. In combination with Figure 4, the coordination control of DG1 and DG2 can enlarge the compensation range of the voltage sag, decrease the DG capacity and decrease the power level of the converter. Its cost drops compared with the architecture in Figure 6 in paper [7].

When the micro-grid feeder line has a short circuit, the DG1 converter is controlled as a voltage source that outputs the voltage component of the lag failure current $90^{\circ}$ to increase the resistance value on the feeder line and restrict the failure current. When transitioning from grid-connected mode to islanded mode in the micro-grid, the DG1 converter switches from a current source to a voltage source and provides rated voltage support at the PCC. Because of the limited space, the detailed control will not be explained here.

\subsection{Control of a Parallel Converter}

The control diagram of a parallel converter is shown in Figure 13. In dq0 coordinates, Equation (5) is its control equation and applies feed-forward control on the load voltage, where $G_{f}(s)$ is the feed-forward function, $R_{p}$ is the equivalent resistance on both ends of $C_{p}$, and $T_{c}$ is the switching cycle of the converter.

Figure 13. Control diagram of the parallel converter.

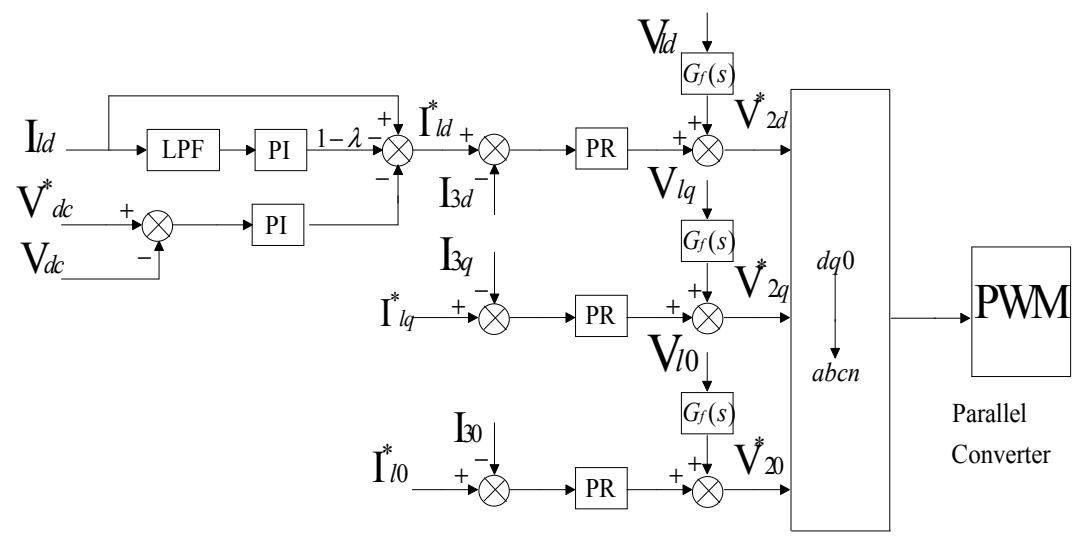




$$
\left\{\begin{array}{l}
G_{f}(s)=\frac{L_{p} C_{p} s^{2}+R_{p} C_{p} s+1}{\left(1+0.5 T_{c} s\right)^{2}} \\
V^{*}{ }_{2 d}=G_{n s}(P R) \cdot\left(I^{*}{ }_{3 d}-I_{3 d}\right)+G_{f}(s) \cdot V_{l d} \\
V^{*}{ }_{2 d}=G_{n s}(P R) \cdot\left(I^{*}{ }_{3 q}-I_{3 q}\right)+G_{f}(s) \cdot V_{l q} \\
V^{*}{ }_{20}=G_{n s}(P R) \cdot\left(I^{*}{ }_{30}-I_{30}\right)+G_{f}(s) \cdot V_{l 0}
\end{array}\right.
$$

Therein, the load current $I_{l d}$ goes through the low pass filter and then passes through the PI regulator to obtain a more precise load fundamental current. After adjusting the value of $\lambda$, the amplitude of the grid-interfacing fundamental current can be changed.

In [21] a strategy for power delivery based on symmetric components during voltage sags was proposed. Through the adjustment of the control parameters, the magnitude of the oscillating power can be smoothly regulated. In this paper, the compensations of harmonic current, reactive current, active current and power sharing are combined and controlled by the DG2 parallel converter. Figure 14 is a simplified single-phase equivalent diagram of Figure $7 \mathrm{a}$, where $I_{s e r 1}$ denotes that DG1 is controlled as a sinusoidal current source; $V_{\text {ser } 2}$ denotes that the DG2 series converter is controlled as a non-sinusoidal voltage source; I I 2 r 2 represents that the DG2 parallel converter is controlled as a non-sinusoidal current source; $V_{\text {par3 } 3}$ represents that DG3 is controlled as a sinusoidal voltage source; $Z_{L d}^{\prime}$ represents the DG3 local load; Zlinel and $Z_{\text {line } 2}$ represent the transmission line impedance between DG1 to DG2 and DG2 to DG3; and $I_{n 2}$ represents the current flowing past $Z_{\text {line } 2 \text {. }}$

Figure 14. Single-line equivalent diagram.

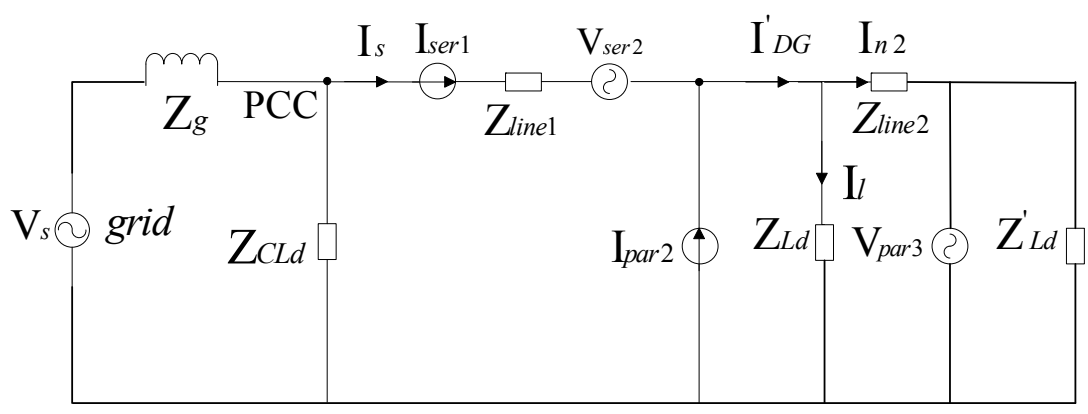

In $\mathrm{dq} 0$ coordinates, the instantaneous power can be controlled by the control of the instantaneous current $I_{d}, I_{q}$ and $I_{0}$ [22], assuming that $P_{\text {Ldav }}$ and $Q_{L q a v}$ are the average active power and average reactive power of the DG2 local load, respectively. $P_{2}, Q_{2}, P_{2}^{\prime}$ and $Q_{2}^{\prime}$ are reactive power and active power provided by DG2 and the utility grid, respectively. $\lambda_{2 P}, \lambda_{2 Q}, \lambda_{2 P}^{\prime}$ and $\lambda_{2 Q}^{\prime}$ are, respectively, the corresponding active and reactive power fractions, as shown in Equation (6):

$$
\left\{\begin{array}{l}
P_{2}=\lambda_{2 P} P_{L d a v} \\
Q_{2}=\lambda_{2 Q} Q_{L d a v} \\
P^{\prime}{ }_{2}=\lambda_{2 P}{ }_{2 P} P_{L d a v} \\
Q^{\prime}{ }_{2}=\lambda^{\prime}{ }_{2} Q_{L d a v}
\end{array}\right.
$$

According to the Kirchhoff Current Law, it can be deduced in dq0 coordinates that: 


$$
\left[\begin{array}{c}
I_{D G d}^{\prime} \\
I_{D G q}^{\prime} \\
I_{D G 0}^{\prime}
\end{array}\right]=\left[\begin{array}{c}
I_{s e r 1 d} \\
I_{s e r 1 q} \\
I_{s e r 10}
\end{array}\right]+\left[\begin{array}{c}
I_{p a r 2 d} \\
I_{p a r 2 q} \\
I_{p a r 20}
\end{array}\right]=\left[\begin{array}{c}
I_{s d} \\
I_{s q} \\
I_{s 0}
\end{array}\right]+\left[\begin{array}{c}
I_{p a r 2 d} \\
I_{p a r 2 q} \\
I_{p a r 20}
\end{array}\right]
$$

In consideration of the DG2 capacity and the necessary power of the local load, there are two situations [4]: (1) the power generated by DG2 cannot meet the demand of local power, and the insufficient power should be provided by DG3 and the utility grid; or (2) the power provided by DG2 is sufficient. It can meet the demand of the local load power. In addition, the surplus power is provided for the local energy storage system and the nearest non-local loads of DG3 (considering the real-time communication protocol and the loss on transmission lines). Therein, $I^{\prime *}{ }_{D G}$ is the reference current of $I_{D G}^{\prime}$ in Figure 14 and $I_{d c}$ is the charging current of capacitance $\mathrm{C}$ on both ends of DG2 in Figure 8; $I^{*}{ }_{l 1}$ is the fundamental current of load; $P^{\prime}{ }_{2}$ and $Q_{2}^{\prime}$ are the power values provided to other local loads, respectively. Therein, the DG3 converter control is a sinusoidal voltage source and its control principles are shown in Figure 17 in Section 5.1.

(1) $\lambda_{2 P}+\lambda^{\prime}{ }_{2 P}<1$ and $\lambda_{2 Q}+\lambda_{2 Q}^{\prime}<1$

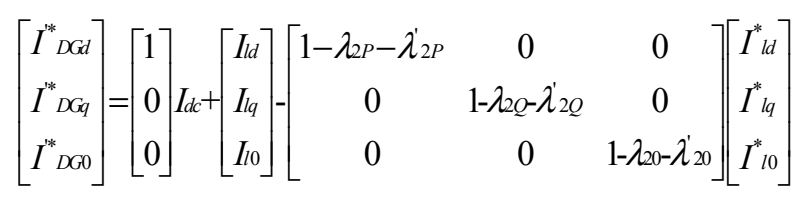

(2) $\lambda_{2 P}+\lambda_{2 P}^{\prime} \geq 1$ and $\lambda_{2 Q}+\lambda^{\prime}{ }_{2 Q} \geq 1$

$$
\left[\begin{array}{c}
I^{* *} D G d \\
I^{* *}{ }_{D G q} \\
I^{*}{ }^{*}{ }_{G 0}
\end{array}\right]=\left[\begin{array}{l}
1 \\
0 \\
0
\end{array}\right] I_{d c}+\left[\begin{array}{c}
I_{l d} \\
I_{l q} \\
I_{l 0}
\end{array}\right]+\frac{3}{2}\left[\begin{array}{ccc}
V_{l d} & V_{l q} & 0 \\
V_{l q} & -V_{l d} & 0 \\
0 & 0 & 0
\end{array}\right]\left[\begin{array}{c}
P_{2}^{\prime} \\
Q_{2}^{\prime} \\
0
\end{array}\right]
$$

Similarly, when $\lambda_{2 P}+\lambda^{\prime}{ }_{2 P}<1$ and $\lambda_{2 Q}+\lambda_{2 Q}^{\prime}>1$, or under other conditions, the power sharing can be analyzed. Due to the limited documentation, the specific control is not described here.

\section{The Improved Direct Control Strategy Based on an Improved Structure of the UPQC}

\subsection{The Improved Direct Control Strategy}

The direct control strategy is stated in Section 1, and the improved direct control strategy is to compensate voltage sags with phase jumps by the coordination control between DG1 and DG2. When DG1 and DG2 coordinate the compensation in the attempt to solve the problem of voltage sags with phase jumps, the DG1 compensation mode is presented in Figure 12a in Section 4.2.1, and the specific control block diagram is shown in Figure 15.

The series converter of DG2 is controlled as a sinusoidal current source, and it applies the principle that the current source produces a larger impedance towards the harmonic voltage and can block the interference on the load voltage. The control schematic diagram is shown in Figure 16, and the control equation is shown in Equation (10). In terms of the influence caused by non-linear, unbalanced and dynamic loads, [23] proposed a method for voltage and frequency control through the combination of deadbeat control and repetitive control in islanded mode. 
Figure 15. Block diagram of coordination control.

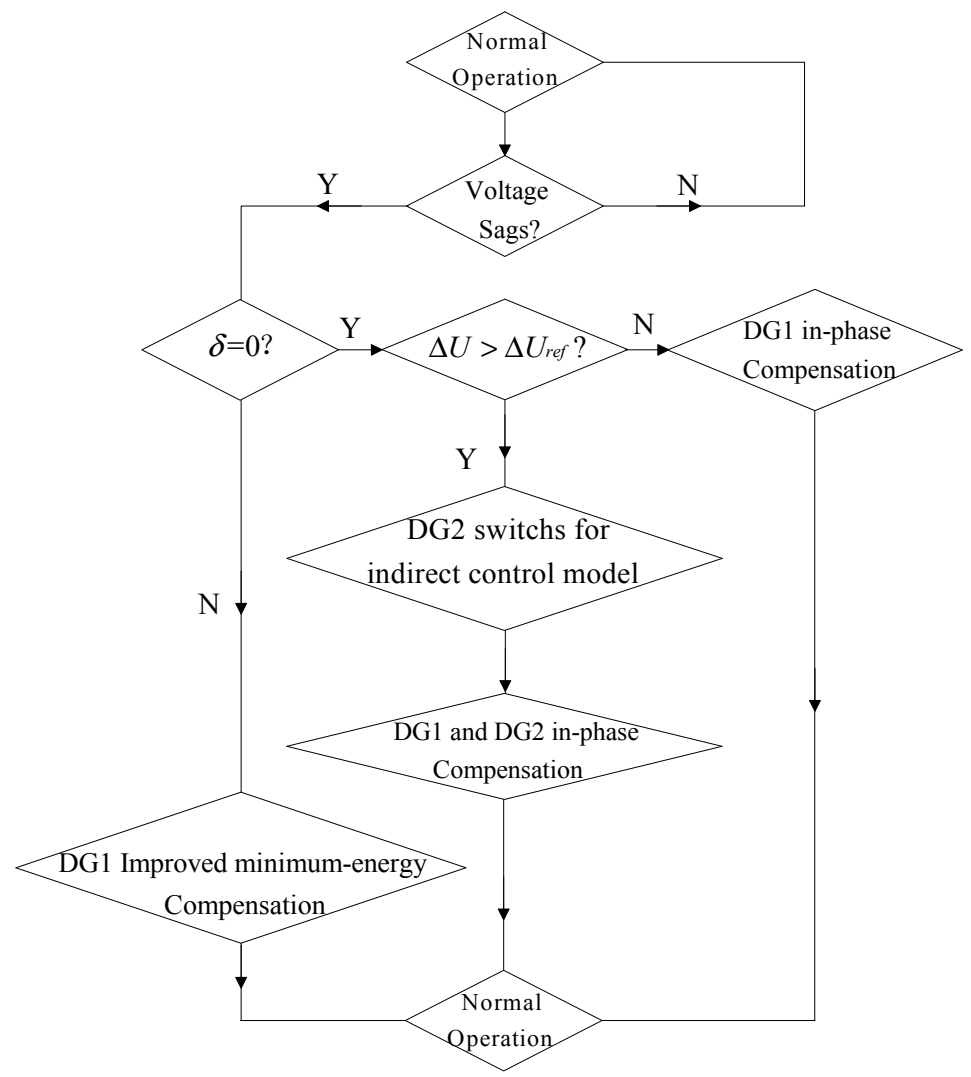

Figure 16. Control diagram of the series converter.

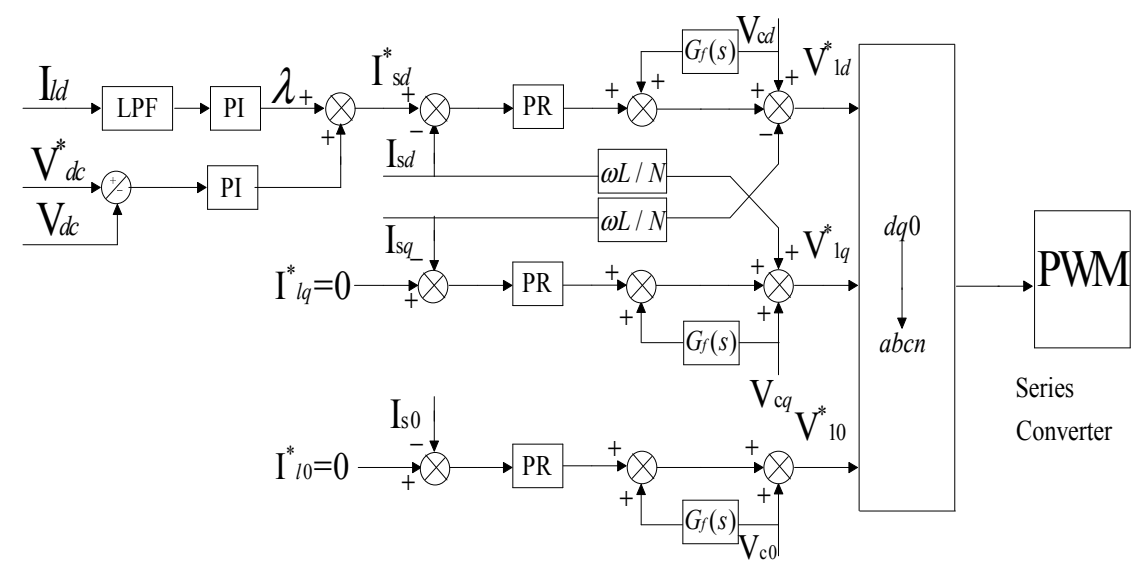

$$
\left\{\begin{array}{l}
V^{*}{ }_{1 d}=\left(1+G_{f}(\mathrm{~s})\right) \cdot V_{c d}-\frac{\omega L}{N} I_{s q}+G_{n s}(P R) \cdot\left(I^{*}{ }_{s d}-I_{s d}\right) \\
V^{*}{ }_{1 q}=\left(1+G_{f}(\mathrm{~s})\right) \cdot V_{c q}+\frac{\omega L}{N} I_{s d}+G_{n s}(P R) \cdot\left(I^{*}{ }_{s q}-I_{s q}\right) \\
V^{*}{ }_{10}=\left(1+G_{f}(\mathrm{~s})\right) \cdot V_{c 0}+G_{n s}(P R) \cdot\left(I^{*}{ }_{s 0}-I_{s 0}\right)
\end{array}\right.
$$


In this paper, the DG2 parallel converter is controlled as a sinusoidal voltage source, and it applies the principle that the voltage source produces less impedance towards the harmonic current. When maintaining the rated voltage on the load terminal, it can absorb harmonic and reactive current. The control schematic diagram is shown in Figure 17 and the control equations are shown in Equations (11) and (12). DG2 and DG3 converters distribute the power based on the principles in Section 4.3. In Figure 15, special attention shall be paid when the voltage drops significantly ( $\Delta U>\Delta U_{\text {ref }}$ ) and the capacity of DG1 is not sufficient for compensation. The series-parallel converter of DG2 is switched to indirect mode, and the voltage sag is compensated by the coordination control of DG1 and DG2.

Figure 17. Control diagram of the parallel converter.

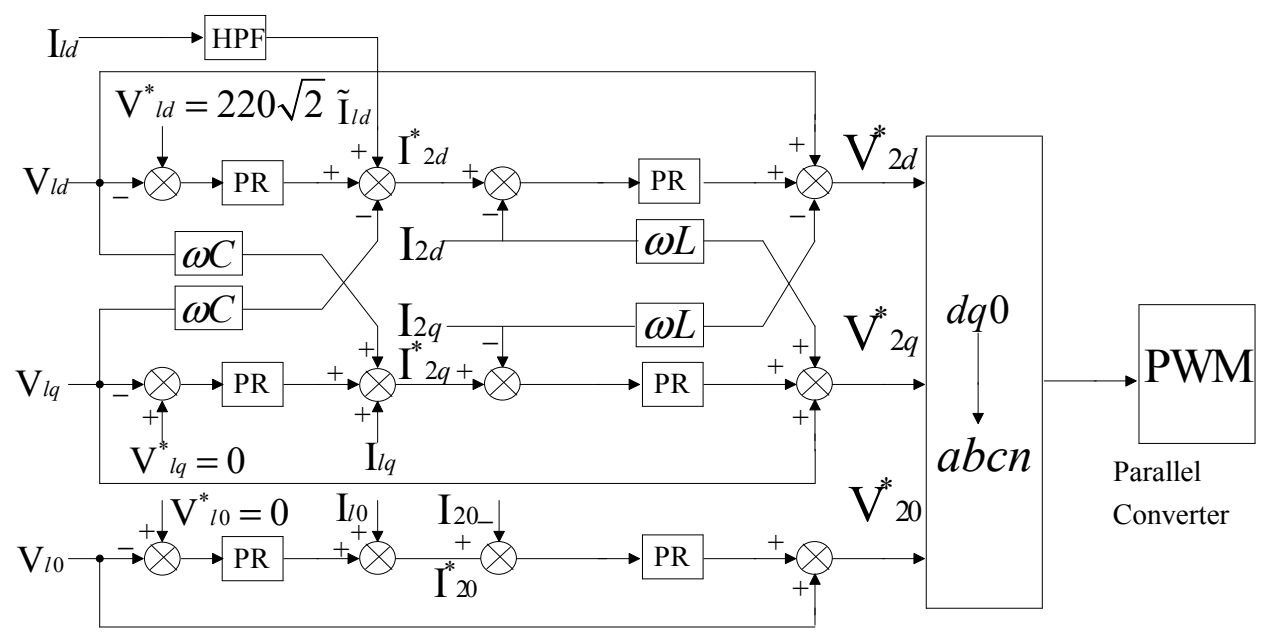

$$
\begin{aligned}
& \left\{\begin{array}{l}
I^{*}{ }_{1 d}=I^{*}{ }_{3 d}-\omega C V_{l q}+G_{n s}(P R) \cdot\left(V^{*}{ }_{l d}-V_{l d}\right) \\
I^{*}{ }_{1 q}=I^{*}{ }_{3 q}+\omega C V_{l d}+G_{n s}(P R) \cdot\left(V^{*}{ }_{l d}-V_{l d}\right) \\
I^{*}{ }_{10}=I^{*}{ }_{30}+G_{n s}(P R) \bullet\left(V^{*}{ }_{l 0}-V_{l 0}\right)
\end{array}\right. \\
& \left\{\begin{array}{l}
V^{*}{ }_{1 d}=V_{l d}-\omega L I_{1 q}+G_{n s}(P R) \cdot\left(I^{*}{ }_{1 d}-I_{1 d}\right) \\
V^{*}{ }_{1 q}=V_{l q}+\omega L I_{1 d}+G_{n s}(P R) \cdot\left(I^{*}{ }_{1 q}-I_{1 q}\right) \\
V^{*}{ }_{10}=V_{l 0}+G_{n s}(P R) \cdot\left(I^{*}{ }_{10}-I_{10}\right)
\end{array}\right.
\end{aligned}
$$

\subsection{The Comparison between Improved Indirect Control and Improved Direct Control Strategies}

Compared with the conventional compensation strategy for voltage sags, the improved indirect control strategy and improved direct control strategy can ensure that the phase angle of the voltage on the load terminal will not change and can decrease the DG capacity and the cost of the converter. In conclusion, the function is more diverse than the conventional compensation method, as shown in Figure 10 in Section 4.1. See Table 1 for the effect comparison between the two improved control strategies. 
Table 1. Effect comparison between the two approaches.

\begin{tabular}{|c|c|c|}
\hline Control strategies & Improved indirect control strategy & Improved direct control strategy \\
\hline Advantages & $\begin{array}{l}\text { In voltage and current compensation, the } \\
\text { amplitude of the required DG voltage is } \\
\text { smaller; targeted at the voltage sag with the } \\
\text { phase jump for a long time whose } \\
\text { compensation effect is better; the effect of } \\
\text { compensating harmonic current is better. }\end{array}$ & $\begin{array}{l}\text { Without detection for the fault and the harmonic } \\
\text { quantity; in voltage and current compensation, } \\
\text { the external interference has little impact on } \\
\text { control parameters; the applied micro-grid } \\
\text { switching from the connected mode to islanded } \\
\text { mode, DG } 2 \text { control mode needs not to switch, } \\
\text { and does not rely on DG1 control mode. }\end{array}$ \\
\hline Disadvantages & $\begin{array}{l}\text { In voltage and current compensation, the } \\
\text { control parameter is rather sensitive to the } \\
\text { external interference; compensation for voltage } \\
\text { sags, voltage swells and the harmonic current, } \\
\text { this method consumes more energy compared } \\
\text { with the latter. The effective utilization rate of } \\
\text { DG is relatively lower. }\end{array}$ & $\begin{array}{l}\text { The ability of the compensating load harmonic } \\
\text { current is little better, especially when the PCC } \\
\text { has voltage distortion; when resolving the } \\
\text { problem of voltage sags with a phase jump for a } \\
\text { long time whose compensation effect is little } \\
\text { better compared with the former. }\end{array}$ \\
\hline Application fields & Small-power DG & Large-power DG \\
\hline
\end{tabular}

\section{The Simulation Verification and Analysis}

The performance of the proposed control arrangement has been verified through a Matlab/Simulink simulation under various operating conditions. The circuit parameters of the simulation are shown in Table 2.

Table 2. Circuit parameters of the system.

\begin{tabular}{ccc}
\hline Parameter & Symbol & Value \\
\hline Rated grid voltage & $V_{s a b c} / f$ & $220 \mathrm{~V} / 50 \mathrm{~Hz}$ \\
Filter inductance & $L_{s} / L_{p}$ & $2 \mathrm{mH} / 2 \mathrm{mH}(\mathrm{ESR} 0.01 \Omega)$ \\
Filter capacitor & $C_{s} / C_{p}$ & $100 \mu \mathrm{F} / 0.5 \mu \mathrm{F}$ \\
Series transformer & $\mathrm{N}$ & $1: 1$ \\
DG voltage & $V_{d c}$ & $790 \mathrm{~V}$ \\
DG-link capacitor & $C$ & $4800 \mu \mathrm{F}$ \\
Switching frequency & $f_{s w}$ & $10 \mathrm{KHz}$ \\
Rectifier impedance & $Z_{r e c}$ & $10+4 \mathrm{j}(\Omega$ before $0.12 \mathrm{~s}) / 5+2 \mathrm{j}(\Omega$ after $0.12 \mathrm{~s})$ \\
\hline
\end{tabular}

(1) Compensation of Unbalanced Three-Phase Voltage Sags and Voltage Distortion

As shown in Figure 18a, the voltage of the PCC happens to drop at $0.02 \mathrm{~s}$, and three-phase voltages (without phase-angle jump) drop $10 \%, 20 \%$ and $30 \%$, and the voltage is injected at $10 \%$ of the third harmonic and $10 \%$ of the fifth harmonic at $0.2 \mathrm{~s}$. After two types of control strategies for compensation, the voltage of the loads is shown in Figures $18 \mathrm{~b}$ and $18 \mathrm{c}$, showing good voltage quality. As shown in Figure $18 \mathrm{~d}$,e, the comparison of the phase c voltage is analyzed before compensation and after compensation. The compensation effect is shown in Table 3. 
Figure 18. Voltage compensation simulation results. (a) The voltage of PCC; (b) Effect comparison with indirect control; (c) Effect comparison with direct control; (d) The comparison after indirect control compensation; (e) The comparison after direct control compensation.

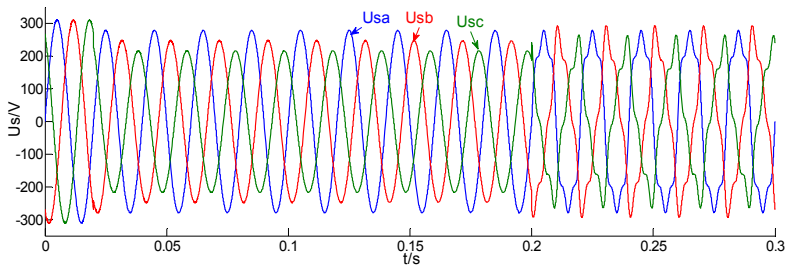

(a)

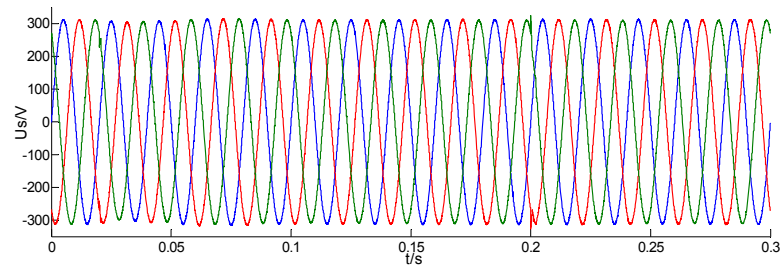

(c)

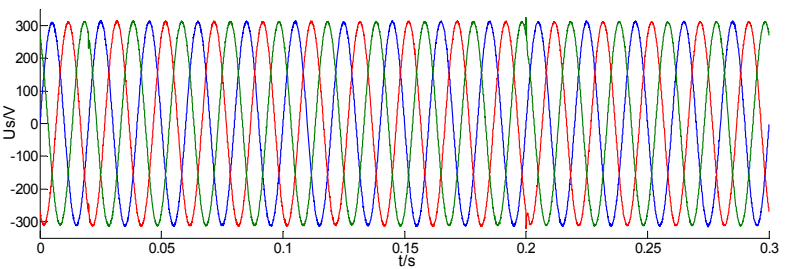

(b)

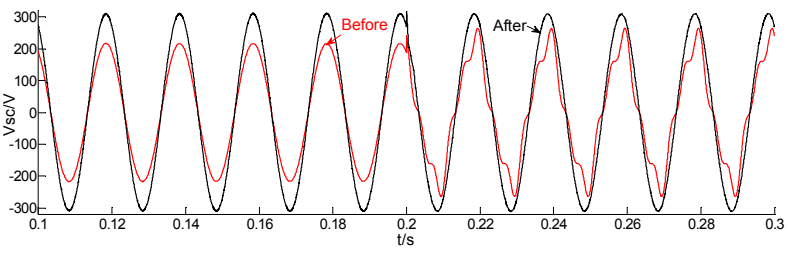

(d)

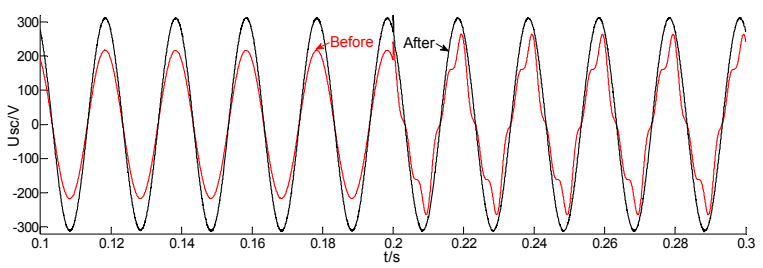

(e)

Table 3. The ratio of the active power provided by the DG2 and the utility grid.

\begin{tabular}{ccc}
\hline Time/Fractions & $\lambda_{2 P} / \mathbf{D G}_{\mathbf{2}}$ & $\lambda_{2 P}^{\prime} /$ Utility grid \\
\hline $0<t<0.12$ & 0 & 1 \\
$0.12<t<0.24$ & 0.15 & 0.85 \\
$0.24<t<0.34$ & 0.3 & 0.7 \\
\hline
\end{tabular}

\section{(2) Compensation of Harmonic Current and Power Sharing}

The current of the nonlinear loads is shown in Figure 19a, and its Total Harmonic Distortion (THD) is shown in Table 3. To detect the dynamic performance of the compensation and power sharing, the three-phase rectifier load is changed at $0.12 \mathrm{~s}$, as shown in Table 2 (the DG2 local loads require more power after $0.12 \mathrm{~s}$ ). Active power fractions supplied by DG2 and the utility grid are, respectively, shown in Table 3. The power sharing between them is shown in Figure 19b. The grid-interfacing current is shown in Figures 19c and 19d after two types of improved control strategies. The THD is shown in Table 4. In particular, the parallel converter not only provides a harmonic current and a reactive current but also provides $15 \%$ of the active current $(0.12<t<0.24)$, as shown in Figure $19 \mathrm{e}$ and Figure 19f. 
Figure 19. Current compensation and power sharing simulation results. (a) The current of nonlinear loads; (b) Power sharing between DG2 and utility grid; (c) The grid-interfacing current with indirect control; (d) The grid-interfacing current with direct control; (e) The compensation current with indirect control; (f) The compensation current with direct control.

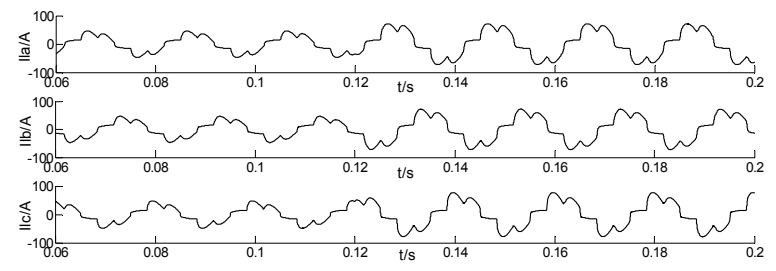

(a)

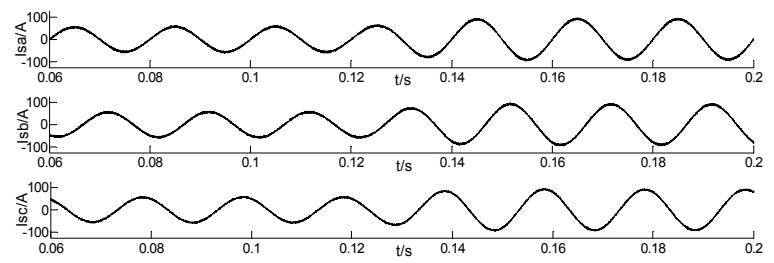

(c)

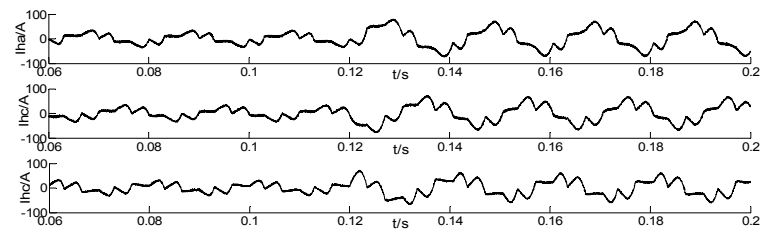

(e)

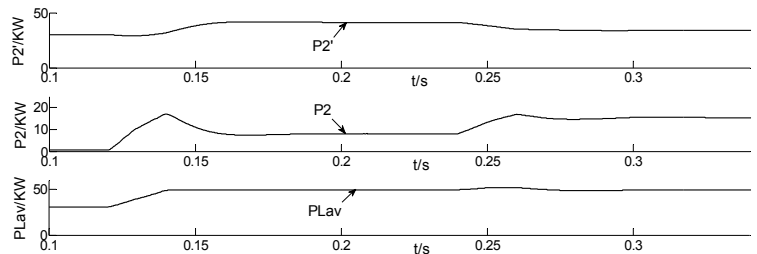

(b)

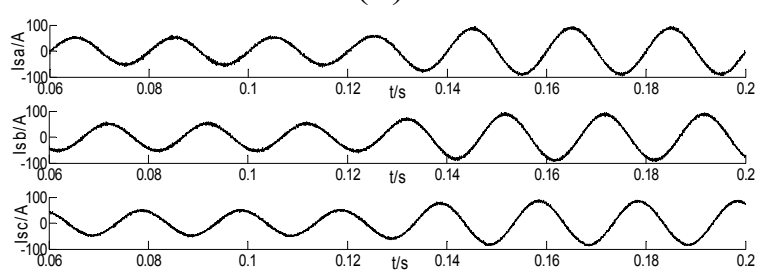

(d)

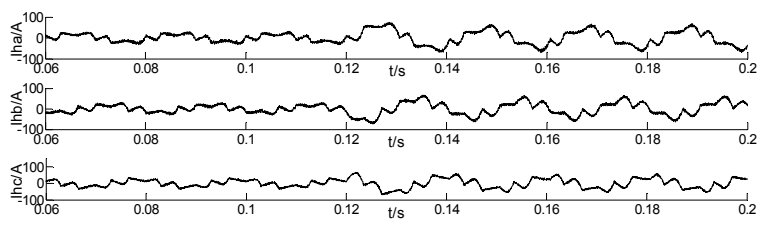

(f)

Table 4. Effect comparison after three types of algorithm compensation.

\begin{tabular}{cccccccc}
\hline $\begin{array}{c}\text { Effect } \\
\text { Compensation }\end{array}$ & $\begin{array}{c}\text { THD of } \\
\text { Phase a } \\
\text { Voltage/(\%) }\end{array}$ & $\begin{array}{c}\text { THD of } \\
\text { Phase b } \\
\text { Voltage/(\%) }\end{array}$ & $\begin{array}{c}\text { THD of } \\
\text { Phase c } \\
\text { Voltage/(\%) }\end{array}$ & $\begin{array}{c}\text { THD of } \\
\text { Phase a } \\
\text { Current/(\%) }\end{array}$ & $\begin{array}{c}\text { THD of } \\
\text { Phase b } \\
\text { Current/(\%) }\end{array}$ & $\begin{array}{c}\text { THD of } \\
\text { Phase c } \\
\text { Current/(\%) }\end{array}$ & $\begin{array}{c}\text { Degree of } \\
\text { unbalanced } \\
\text { voltage/(\%) }\end{array}$ \\
\hline $\begin{array}{c}\text { Before } \\
\text { Compensation }\end{array}$ & $\begin{array}{c}14.14 \\
\text { (after 0.2 s) }\end{array}$ & $\begin{array}{c}14.14 \\
\text { (after 0.2 s) }\end{array}$ & $\begin{array}{c}14.14 \\
\text { (after 0.2 s) }\end{array}$ & 13.61 & 15.45 & 17.37 & 5.79 \\
\hline Indirect Control & 0.30 & 0.33 & 0.37 & 2.76 & 3.69 & 3.30 & 0.32 \\
\hline Direct Control & 0.21 & 0.25 & 0.21 & 2.93 & 3.72 & 3.77 & 0.18 \\
\hline
\end{tabular}

(3) Compensation of Voltage Sags with Phase-Angle Jumps

As shown in Figure 20a, the voltage of the PCC happens to drop $40 \%$ with a $30^{\circ}$ jump at $0.02 \mathrm{~s}$. The compensation voltage of the DG1 series converter is shown in Figure 20b. The terminal voltage A (Figure 8) is shown in Figure 20c. The voltage of the loads is shown in Figure 20d,e after improved indirect and improved direct control strategies, showing good voltage quality. As shown in Figure 20f,g,h, the comparison of the phase voltage is analyzed after improved indirect compensation, improved direct compensation and the conventional minimum-energy compensation. The effect comparison among the three methods is shown in Table 5. 
Figure 20. The compensation of the voltage sags with phase-angle jump simulation results and comparison. (a) The voltage sags of the PCC with a $30^{\circ}$ jump; (b) The compensation voltage of $\mathrm{DG}_{1}$; (c) Terminal voltage A after DG1 compensation; (d) The voltage of the loads after improved indirect compensation; (e) The voltage of the loads after improved direct compensation; (f) The comparison after improved indirect control compensation; (g) The comparison after improved direct control compensation; (h) The comparison after conventional min-energy compensation.

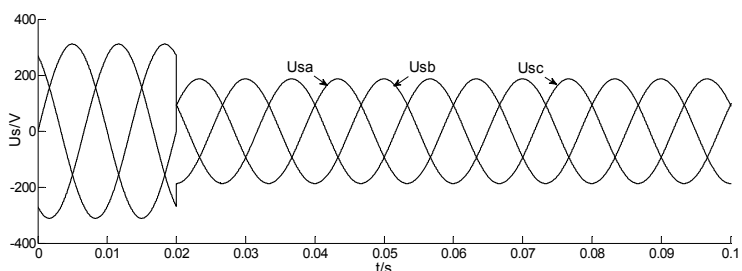

(a)

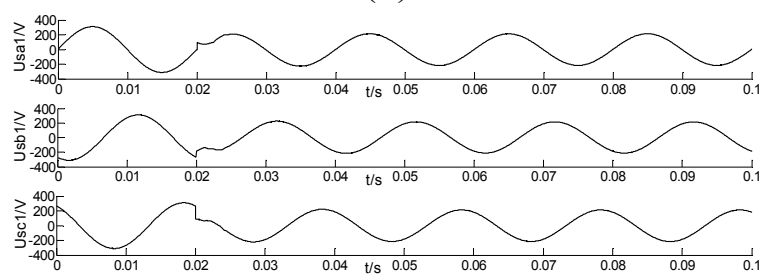

(c)

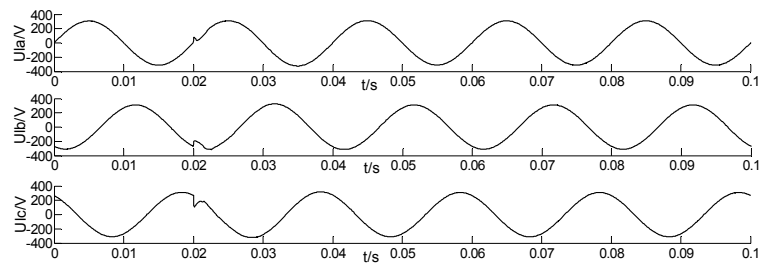

(e)

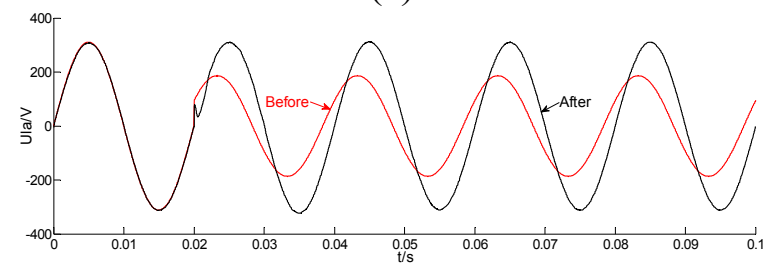

(g)

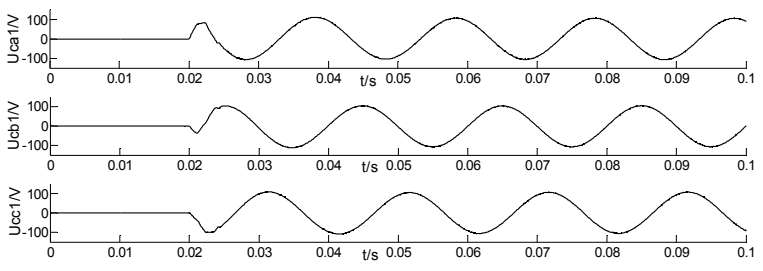

(b)

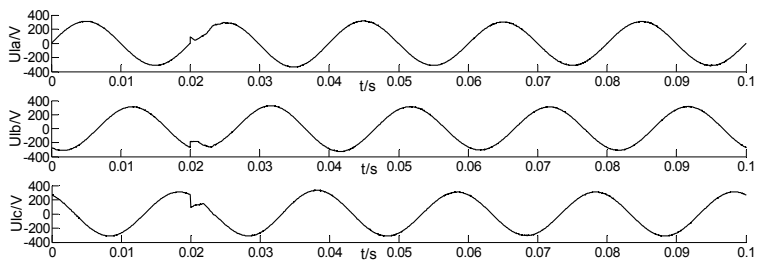

(d)

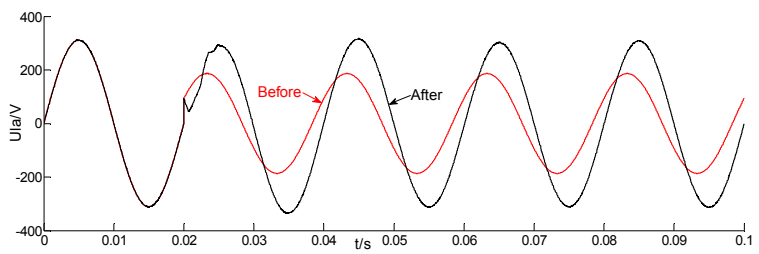

(f)

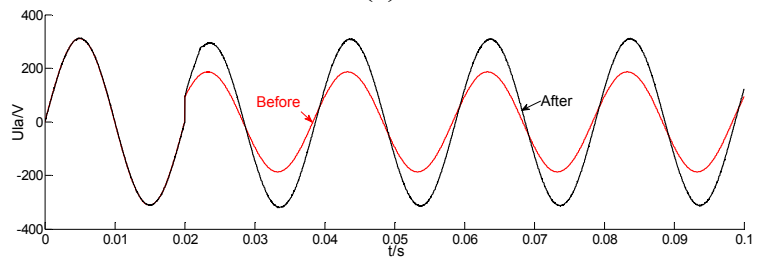

(h)

Table 5. Effect comparison between the three types of algorithms.

\section{Compensation methods}

Improved indirect method Improved direct method

Conventional method
The actual jumped angle after compensation $/\left(^{\circ}\right)$

0.6353

0.5906

22.3783
The ideal jumped angle after compensation $/\left({ }^{\circ}\right)$

0

0

23.1301

\section{Conclusions}

In an attempt to solve the energy security problem, this paper proposes a power supply scheme with features of low carbon, environmental protection, efficient utilization and excellent reliability of 
supply. Through the reasonable allocation of DG capacity and location and the coordination control of series-parallel converters between DG, a micro-grid based on the improved UPQC architecture is proposed. The improved indirect and improved direct control strategies in this paper have overcome the defects of conventional voltage sag compensation algorithms to ensure that the load voltage has no phase-angle jumps, which cannot only increase DG compensation ability and range but also reduce the capacity and the cost of the converter. In addition, this architecture can reduce the shock of micro-grid switching between grid-connected mode and islanded mode. For the parallel converter, the combined control on the compensation of the harmonic current, reactive current, active current and power sharing is of valuable practical significance to power complementary and rational utilization of DGs in the micro-grid. Additionally, the corresponding DG application fields are proposed, depending on the advantages and disadvantages of the two improved control strategies.

\section{Acknowledgments}

The work was supported by the Fundamental Research Funds for the Central Universities of China (No.2012JBM098).

\section{Conflicts of Interest}

The authors declare no conflict of interest.

\section{References}

1. Marnay, C. Micro-Grids and Heterogeneous Security, Quality, Reliability, and Availability. In Proceedings of Power Conversion Conference, Nagoya, Japan, 2-5 April 2007; pp. 629-634.

2. Li, Y.W.; Vilathgamuwa, D.M.; Loh, P.C. A grid-interfacing power quality compensator for three-phase three-wire micro-grid applications. IEEE Trans. Power Electron. 2006, 21, 1021-1031.

3. Li, Y.W.; Vilathgamuwa, D.M.; Loh, P.C. Micro-grid power quality enhancement using a three-phase four-wire grid-interfacing compensator. IEEE Trans. Ind. Appl. 2005, 41, 1707-1719.

4. Majumder, R.; Ghosh, A.; Ledwich, G.; Zare, F. Load sharing and power quality enhanced operation of a distributed micro-grid. IET Renew. Power Gener. 2009, 3, 109-119.

5. Shahnia, F.; Majumder, R.; Ghosh, A. Operation and control of a hybrid micro-grid containing unbalanced and nonlinear loads. IEEE Trans. Electr. Power Syst. Res. 2010, 80, 954-965.

6. Wang, F.; Duarte, J.L.; Hendrix, M. Control of Grid-Interfacing Inverters with Integrated Voltage Unbalance Correction. In Proceedings of IEEE Power Electronics Specialists Conference, Rhodes, Greece, 15-19 January 2008; pp. 310-316.

7. Wang, F.; Duarte, J.; Hendrix, M. Grid-interfacing converter systems with enhanced voltage quality for micro-grid application - Concept and implementation. IEEE Trans. Power Electron. 2011, 26, 3501-3513.

8. Shen, G.Q.; Xu, D.H.; Cao, L.P.; Zhu, X.C. An improved control strategy for grid-connected voltage source inverters with an LCL filter. IEEE Trans. Power Electron. 2008, 23, 1899-1906.

9. Papadimitriou, C.N.; Vovos, N.A. Transient response improvement of microgrids exploiting the inertia of a doubly-fed induction generator (DFIG). Energies 2010, 3, 1049-1066. 
10. Zamani, M.; Yazdani, A.; Sidhu, T. A control strategy for enhanced operation of inverter-based micro-grids under transient disturbances and network faults. IEEE Trans. Power Deliv. 2012, 27, 1737-1747.

11. Majumder, R.; Ghosh, A.; Ledwich, G. Power management and power flow control with back-to-back converters in a utility connected micro-grid. IEEE Trans. Power Syst. 2010, 25, 821-834.

12. Shi, X.L.; Jiang, J.C.; Guo, X.T. An efficiency-optimized isolated bidirectional dc-dc converter with extended power range for energy storage systems in microgrids. Energies 2013, 6, 27-44.

13. Zhang, N.; Gu, W.; Yu, H.J.; Liu, W. Application of coordinated SOFC and SMES robust control for stabilizing tie-line power. Energies 2013, 6, 1902-1917.

14. Xiao, Z.; Li, T.H.; Huang, M.; Shi, J.H.; Yang, J.J.; Yu, J.; Wu, W. Hierarchical MAS based control strategy for micro-grid. Energies 2010, 3, 1622-1638.

15. Katiraei, F.; Iravani, M.R.; Lehn, P.W. Micro-grid autonomous operation during and subsequent to islanding process. IEEE Trans. Power Deliv. 2004, 20, 248-257.

16. Zhang, G.R.; Zhang, T.L.; Ding, M.; Su, J.H.; Wang, H.N.; Lv, S.X.; Chen, J.L.; Xu, H.L. Simulation research on unified power quality conditioner with PV grid connected generation. Proc. CSEE 2007, 27, 82-86.

17. Hsn, B.; Bae, B.; Kim, H.; Baek, S. Combined operation of unified power-quality conditioner with distributed generation. IEEE Trans. Power Deliv. 2006, 21, 330-338.

18. Cai, L.H.; Jing, P.; Wu, S.Y.; Li, H.X. Control strategies of dynamic voltage restorer. Electr. Power Automot. Equip. 2007, 27, 22-25.

19. Vilathgamuwa, D.M.; Perera, A.A.D.R.; Choi, S.S. Voltage sag compensation with energy optimized dynamic voltage restorer. IEEE Trans. Power Deliv. 2003, 18, 928-936.

20. Choi, S.S.; Li, B.H.; Vilathgamuwa, D.M. Dynamic voltage restoration with minimum energy injection. IEEE Trans. Power Syst. 2000, 15, 51-57.

21. Wang, F.; Duarte, J.; Hendrix, M. Pliant active and reactive power control for grid-interactive converters under unbalanced voltage dips. IEEE Trans. Power Electron. 2011, 26, 1511-1521.

22. Zhou, N.C.; Chi, Y.; Wang, Q.G. Control strategies for micro-grid containing non-linear and unbalanced loads. Autom. Electr. Power Syst. 2011, 35, 61-66.

23. Mohammad, D.; Amirnaser, Y. Islanded-mode control of electronically coupled distributed-resource units under unbalanced and nonlinear load conditions. IEEE Trans. Power Deliv. 2011, 26, 661-673.

(C) 2013 by the authors; licensee MDPI, Basel, Switzerland. This article is an open access article distributed under the terms and conditions of the Creative Commons Attribution license (http://creativecommons.org/licenses/by/3.0/). 